\title{
Research on Modal Parameter Identification Method of Railway Carbody Based on 6-DOF Vibration Test Bench
}

\author{
Jia Zhang, Jinghan Wen, Ye Song*, Pingbo Wu \\ State Key Laboratory of Traction Power, Southwest Jiaotong University, Chengdu \\ 610031, China \\ National Science Fund Subsidized Project 52002341 \\ *Corresponding Author, sy8621@163.com
}

\begin{abstract}
In order to avoid the additional influence on the test results caused by the inconsistency between the boundary conditions of the carbody and the reality when using the vibration exciter or hammer to test the free mode of the carbody, a 6-DOF vibration test bench is tried to simulate the actual motion posture of the carbody to test its modal parameters. For in-depth discussion, a full-scale virtual prototype of the 6-DOF vibration test bench was built, and on this basis, the test bench-carbody rigidflexible coupling virtual test system was established. According to the modal frequency range of the carbody to be tested and the actual load capacity of the test bench, the excitation frequency and amplitude of the test bench are determined. Through the virtual modal test, it is determined that the carbody should be elastically supported when testing the modal parameters of the carbody by using the vibration test bench, so as to accurately obtain the modal parameters of the carbody.
\end{abstract}

\section{Keywords}

Railway vehicle body; Modal test; 6-DOF vibration test bench; Virtual prototype

\section{Introduction}

When a vehicle is running, it always receives various load inputs from the environment. These loads are transmitted by the vehicle system itself, and finally appear as the vibration response of the various structures of the vehicle. In order to avoid the harm caused by excessive vibration response, it is necessary to test and analyze the vibration source and the vibration characteristics of the structure itself to control the vibration. Therefore, it is necessary to test the modal information of carbody. When testing structural modal parameters, it is necessary to apply excitation to the tested part. The traditional excitation methods are hammer excitation and exciter excitation [1]. For the heavy structure such as carbody, the hammer will make the signal underload at the measuring point which is far away from the excitation position due to its low excitation energy, therefore, only partial modal information of the tested carbody can be obtained. Compared with the hammer, the excitation energy 
of exciter is slightly higher and more evenly distributed, and the quality of test data is usually higher. In order to fully identify the modal information of the carbody, two or four exciters are usually needed to excite the carbody at the same time [2], but the structure of exciter is heavy, and the installation position needs to avoid the node position of the modal shapes of the carbody. It brings great difficulties to the installation work. During the test, the support state and excitation position of the carbody are inconsistent with the actual working state of the carbody, and there is also the problem of incomplete identification of the modal parameters of the carbody [35]. In order to identify the modal parameters of the carbody under working conditions more comprehensively and truly, it is considered loading the carbody by simulating the actual motion posture of the train on a 6-DOF vibration test bench, and test its modal parameters.

\section{$2 \quad$ Virtual Test System Modeling}

\subsection{Structure composition of 6-DOF test bench}

The 6-DOF test bench consists of front and rear subsystems, as shown in Figure 1. The two subsystems are symmetrical in structure. During the test, the structure to be tested is fastened on the upper surfaces of the front and rear subsystems by clamps, and the two subsystems cooperate to drive the structure to be tested to move in space to complete the test. Figure 2 shows the specific structure of each subsystem, including 8 components. The names and functions of each component are shown in Table 1, and the maximum excitation frequency of the test bench can reach $50 \mathrm{~Hz}$.

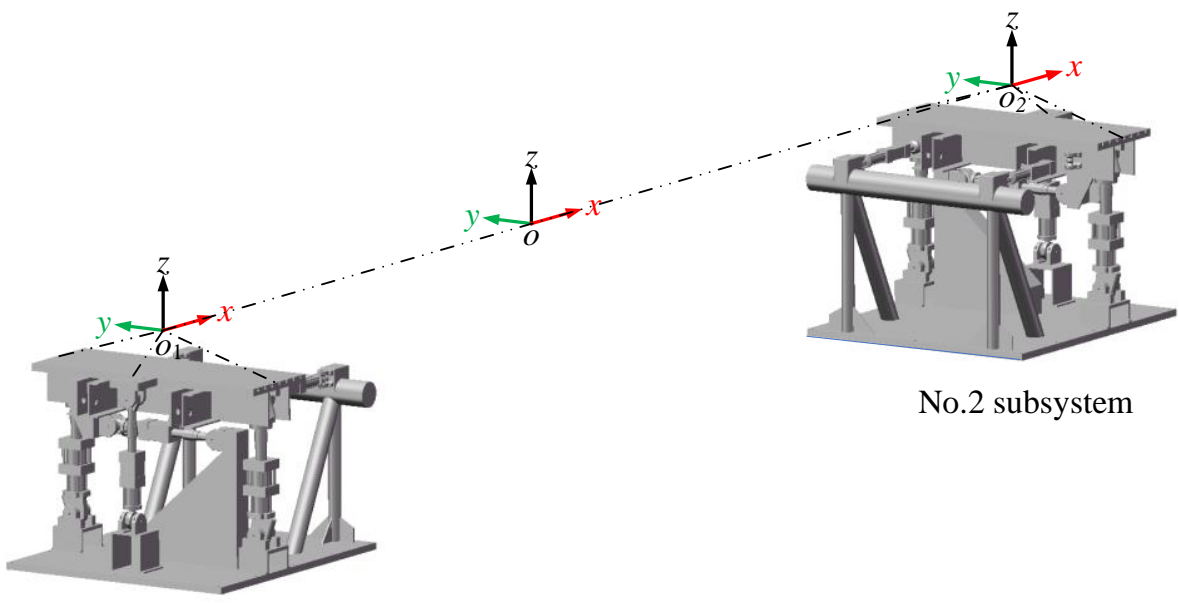

No.1 subsystem

Figure $16-\mathrm{DOF}$ vibration test bench.

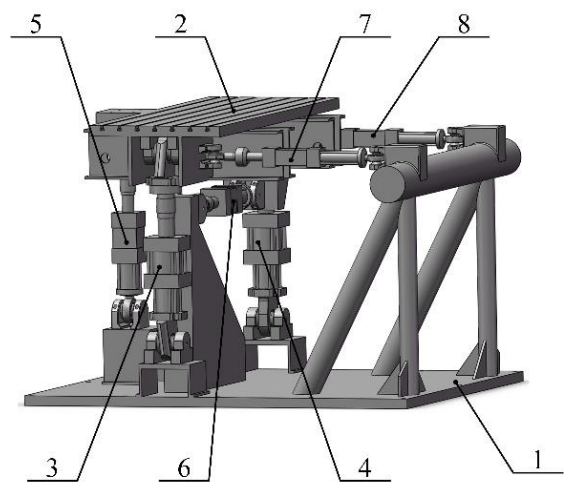


Figure 2 Composition of test bench subsystem.

Table 1 The name and function of each component of the test bench subsystem.

\begin{tabular}{ccc}
\hline Number & Item & Function \\
\hline 1 & The base of test bench & $\begin{array}{c}\text { Support test bench system } \\
\text { Mith } 6 \text { degrees of freedom of } \\
\text { movement in space }\end{array}$ \\
2 & Votion platform & $\begin{array}{c}\text { Coordinate action, drive the } \\
\text { motion platform to move }\end{array}$ \\
$6,4,5$ & Lateral actuator & according to the target posture. \\
\end{tabular}

\subsection{Virtual prototype modeling of test bench}

In order to deeply discuss the problems existing in testing the modal parameters of carbody with vibration test bench, a full-scale virtual prototype of the 6-DOF vibration test bench was built with the multi-body dynamics software SIMPACK [6], as shown in Figure 3. All parts of the virtual prototype are modeled by rigid bodies, in which the base of test bench is fixedly connected with the geodetic coordinate system and has 0 degrees of freedom of movement. The lower spherical hinge of each actuator is connected with the base of test bench by spherical joint, which has three rotational degrees of freedom relative to the geodetic coordinate system. The upper spherical hinge of each actuator is connected with the top moving platform by spherical hinge joint, which has three rotational degrees of freedom. The motion platform has six degrees of freedom relative to the geodetic coordinate system, and its motion attitude depends entirely on the driving of the actuators below. The actuating rod of each actuator can extend or retract in the cylinder, and the time function can be input in the virtual prototype to control the action of each actuator. The virtual prototype of the test bench completely restores the physical model of the test bench, which can be used to study the method of vehicle body modal test with vibration test bench more efficiently and deeply.

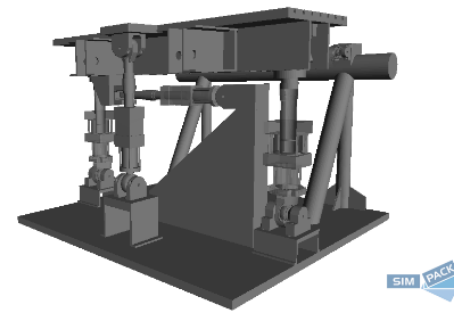

Figure 3 The virtual prototype of 6-DOF vibration test bench.

\subsection{Computational modal analysis of the vehicle body}

Taking the structural carbody of a certain type of EMU as the research object, firstly, the finite element model of this type of EMU carbody is established. The finite element model of this carbody is divided by shell elements, with a total of 487,124 nodes, as shown in the Figure 4. The first six-order mode information of the carbody 
is obtained by finite element calculation, and the amplitudes and frequencies of each order mode are shown in Figure 5. They are the first-order diamond mode, the firstorder vertical bending mode, the first-order breathing mode, the first-order torsion mode, the second-order breathing mode and the first-order transverse bending mode.

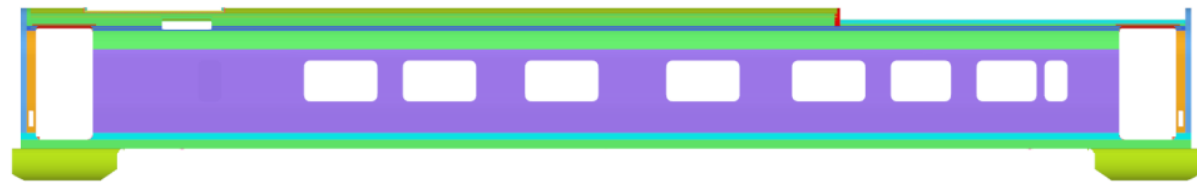

Figure 4 Carbody finite element model.
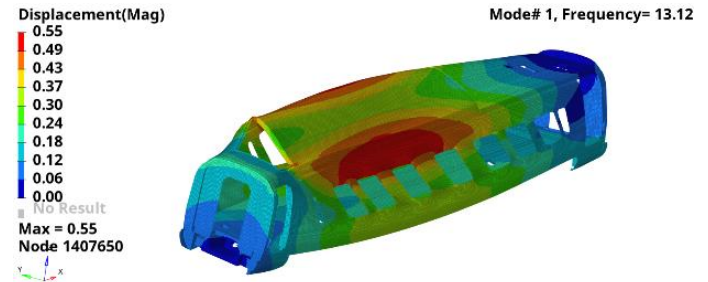

a) The first-order diamond mode $(13.12 \mathrm{~Hz})$

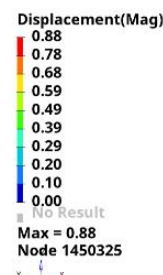
Node 1450325

c) The first-order breathing mode

$(17.75 \mathrm{~Hz})$

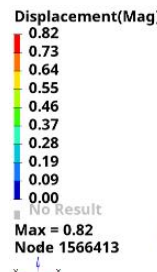

e) The second-order breathing mode

$(21.09 \mathrm{~Hz})$

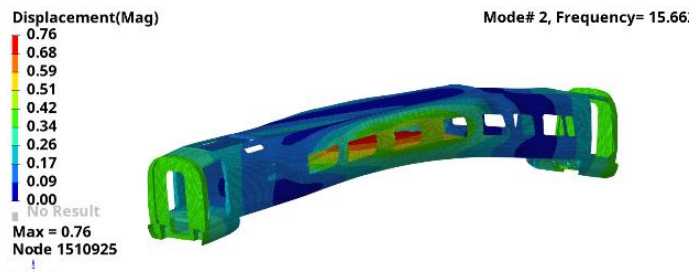

b) The first-order vertical bending mode $(15.66 \mathrm{~Hz})$

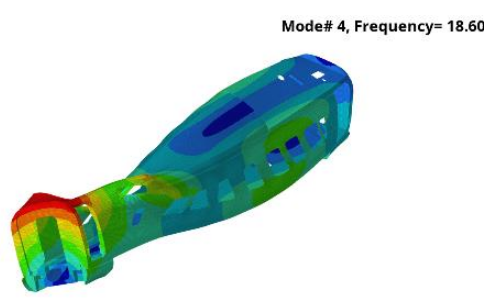

d) The first-order torsion mode $(18.60 \mathrm{~Hz})$
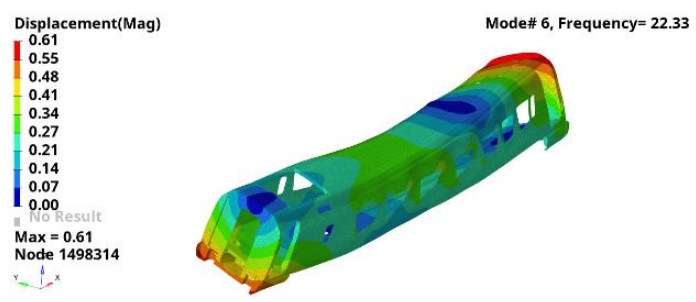

f) The first-order transverse bending mode

$(22.33 \mathrm{~Hz})$

Figure 5 The first six-order mode information of the carbody.

\subsection{Establishment of the test bench-carbody rigid-flexible coupling model}

In order to study the vibration characteristics of the carbody under external excitation, it is necessary to treat the finite element model of the carbody to be tested as a flexible body model. In order to avoid the shortage of computer computing resources caused by the excessive number of freedom degrees in the original model, the substructure method is used to reduce the full freedom degrees of the original carbody finite element model based on Guyuan Reduction Theory [7-9]. The substructure with reduced degree of freedom is used to generate the flexible body model of the carbody to be tested. The Table 2 shows the comparison between the 
modal information of substructure with reduced degree of freedom and the modal information of full degree of freedom carbody. It can be seen that they are very close, and the error is less than $1 \%$, which meets the engineering requirements. The modal information of substructure is taken as the theoretical value of carbody free mode.

On the basis of the virtual prototype of the 6-DOF vibration test bench, the flexible model of the carbody to be tested is added, and the rigid-flexible coupling model of the test bench-carbody is established, as shown in Figure 6.

Table 2 Comparison of modal information before and after the reduction of the degree of freedom of the carbody.

\begin{tabular}{cccc}
\hline Modal shape & $\begin{array}{c}\text { Full freedom } \\
\text { Modal } \\
\text { frequency/Hz }\end{array}$ & $\begin{array}{c}\text { Free modal } \\
\text { frequency of } \\
\text { substructure } \\
/ \mathrm{Hz}\end{array}$ & $\begin{array}{c}\text { Relative } \\
\text { error (\%) }\end{array}$ \\
\hline The first-order diamond mode & 13.11 & 13.13 & 0.15 \\
The first-order vertical bending mode & 15.65 & 15.73 & 0.51 \\
The first-order breathing mode & 17.72 & 17.86 & 0.79 \\
The first-order torsion mode & 18.58 & 18.63 & 0.27 \\
The second-order breathing mode & 21.09 & 21.26 & 0.81 \\
The first-order transverse bending mode & 22.28 & 22.34 & 0.27 \\
\hline
\end{tabular}

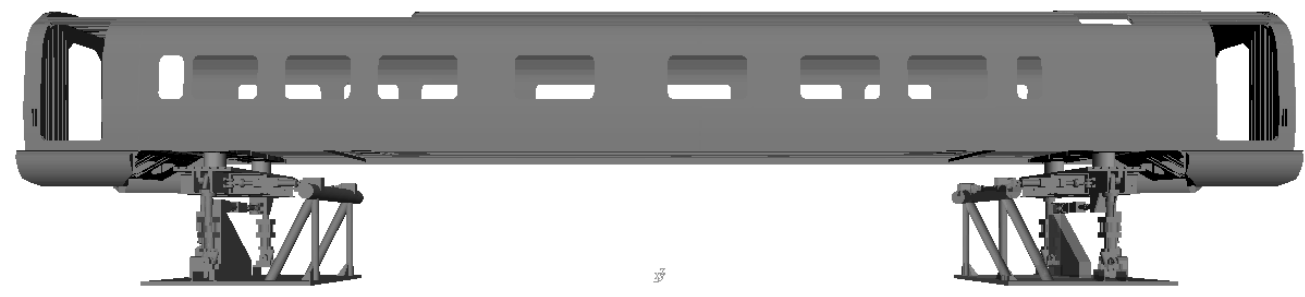

Figure 6 Rigid-flexible coupling model of test bench and carbody.

\subsection{Arrangement of measuring points for acceleration of vehicle body}

In order to obtain the vibration response of the carbody, seven test sections are selected on the carbody [10-11], and four acceleration measuring points are symmetrically arranged in each section. At the same time, in order to monitor the acceleration amplitude at the interface between the carbody and the test fixture, an acceleration measuring point is arranged on each of the four air spring mounting seats of the car body, and there are 32 three-phase acceleration measuring points on the whole vehicle. Figure 7 shows the distribution diagram of acceleration measuring points. 


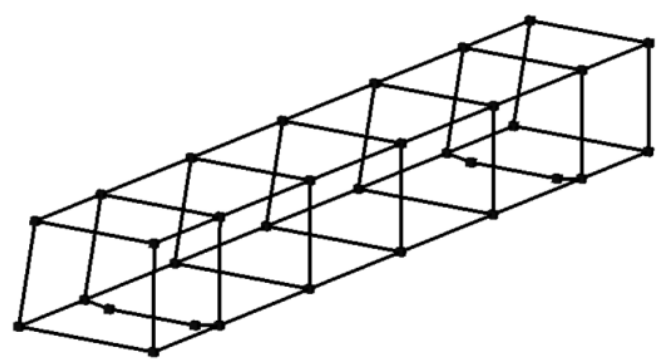

Figure 7 The distribution diagram of acceleration measuring points.

\section{Selection of Excitation Signal}

In order to obtain the modal information of the structure carbody to be tested more truly and comprehensively, simulate the actual movement posture of the carbody and load the structure of carbody to be tested with sinusoidal displacement sweep frequency. There are six typical motion postures when the carbody is running along the line [12], as shown in the Figure 8: which are the telescopic posture of translation along the $\mathrm{X}$ axis; the vertical posture of translation along $\mathrm{Z}$ axis; the lateral movement posture of translation along $\mathrm{Y}$ axis; rolling posture around the $\mathrm{X}$ axis; pitching posture around $\mathrm{Y}$ axis and yawing posture around the $\mathrm{z}$ axis. According to the finite element modal results of the carbody, the first six modal frequencies of the carbody are within the range of $30 \mathrm{~Hz}$. Therefore, controlling the test bench and drive the carbody to sweep from 0 to $30 \mathrm{~Hz}$ according to various typical motion postures. Combined with the load capacity of the test bench, the maximum displacement amplitude when the test bench drives the carbody to simulate various typical motion postures is calculated.

(1) The test bench drives the carbody to do floating and sinking frequency sweep loading:

When the test bench drives the carbody to float and sink, the vertical actuators play the main driving role. The vertical rated load capacity of the test bench is $250 \mathrm{t}$, that is $2.4 \times 10^{6} \mathrm{~N}$. When the test bench drives the carbody to simulate the actual floating and sinking motion to do sinusoidal frequency sweep, the maximum loading frequency is $f$, the maximum vertical displacement is $A$, and the total mass of the carbody and the test bench is recorded as $M$, then the maximum total vertical load that the vertical actuator bears during the test can be expressed as:

$$
F_{\max }=M \times A \times(2 \times \pi \times f)^{2}
$$

Then there should be:

$$
F_{\max } \leq 2.4 \times 10^{6}
$$

According to formula (3-1) and formula (3-2), the total weight of the car body and the test bench is 21 tons, the maximum loading frequency of the virtual test is 30 $\mathrm{Hz}$, and according to the above method, the maximum vertical displacement $A$ of the test bench is $\pm 3.2 \mathrm{~mm}$;

(2) The test bench drives the carbody to do lateral frequency sweep loading:

When the test bench is driven to simulate the lateral movement posture of the carbody for frequency sweep loading, the main driving actuators are the front and rear lateral actuators, the maximum lateral load capacity of the test bench is $50 \mathrm{t}$. 
According to formula (3-1), the maximum lateral loading displacement $A$ of the test bench for frequency sweep loading is $\pm 0.6 \mathrm{~mm}$;

(3) The test bench drives the carbody to do yawing frequency sweep loading:

Drive the test bench to simulate the shaking posture of the carbody for sweeping frequency loading, and the main driving actuator is the lateral actuator. Suppose the maximum loading frequency is $f$, the maximum rotation angle is $A$, and the moment of inertia of the carbody and the test bench as a whole around the axis of $\mathrm{Z}$ is $I_{z z}$ $\left(1.5 \times 10^{6} \mathrm{~kg} \cdot \mathrm{m}^{2}\right)$, when yawing, the stress of each lateral actuator is:

$$
F=\frac{2 \times I_{z z} \times A \times(2 \times \pi \times f)^{2}}{l}
$$

In formula (3-3), $l$ is the longitudinal distance of the lateral actuators of the front and rear subsystems of the test bench.

The maximum load capacity of a single lateral actuator is 25 tons. According to the current state of the virtual test bench and the carbody to be tested, the maximum yawing angle $A$ is 0.003 degrees when the simulated yawing posture is loaded by sweeping frequency.

(4) The test bench drives the carbody to do nodding frequency sweep loading:

When the test bench drives the carbody to simulate the nodding posture for sweeping frequency loading, the vertical actuator is the main driving actuator. The maximum loading frequency is $f$, the maximum nodding angle is $A$, and the moment of inertia of the test carbody and the test bench as a whole around the axis of Y is $I_{\mathrm{yy}}$ $\left(1.5 \times 10^{6} \mathrm{~kg} \cdot \mathrm{m}^{2}\right)$, when nodding, the resultant force on the actuator in the vertical direction of each subsystem is:

$$
F=\frac{2 \times I_{\mathrm{yy}} \times A \times(2 \times \pi \times f)^{2}}{l}
$$

In formula (3-4), $l$ is the longitudinal distance between the vertical actuators on the same side of the two subsystems in front and rear the test bench.

The maximum vertical load capacity of a single test bench subsystem is 125 tons. According to the current state of the virtual test bench and the carbody to be tested, when the simulated nodding motion is loaded by sweeping frequency, the maximum nodding angle $A$ is 0.02 degrees.

(5) The test bench drives the carbody to do rolling frequency sweep loading:

When the test bench drives the carbody to simulate the rolling motion posture for sweeping frequency loading, the vertical actuator is the main driving actuator. The maximum loading frequency is $f$, the maximum nodding angle is $A$, and the moment of inertia of the carbody and the test bench as a whole around the axis of $\mathrm{X}$ is $I_{\mathrm{xx}}$ $\left(5.6 \times 10^{4} \mathrm{~kg} \cdot \mathrm{m}^{2}\right)$. When rolling, the resultant force of the vertical actuators on the same side of the front and rear subsystems is:

$$
F=\frac{2 \times I_{\mathrm{xx}} \times A \times(2 \times \pi \times f)^{2}}{l}
$$


In formula (3-5), $l$ is the lateral distance between the vertical actuators inside and outside a single subsystem of the test bench.

The maximum load of the vertical actuators on the same side of the two subsystems is 100 tons. Combined with the current state of the virtual test bench and the carbody to be tested, it is calculated that the maximum angle $A$ is 0.04 degrees when the simulated rolling motion is loaded by sweeping frequency.

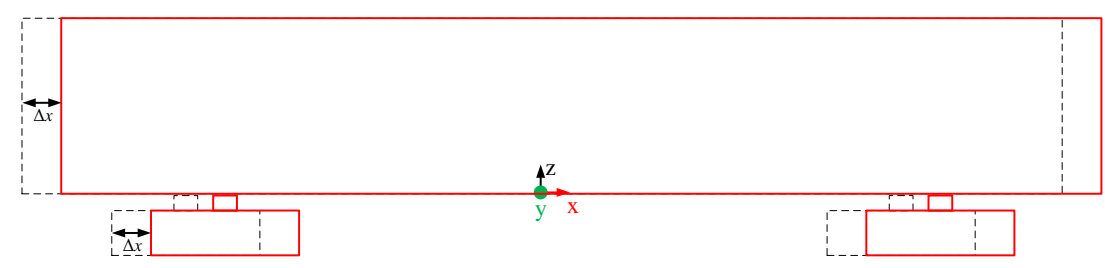

a) Telescopic movement of the carbody.

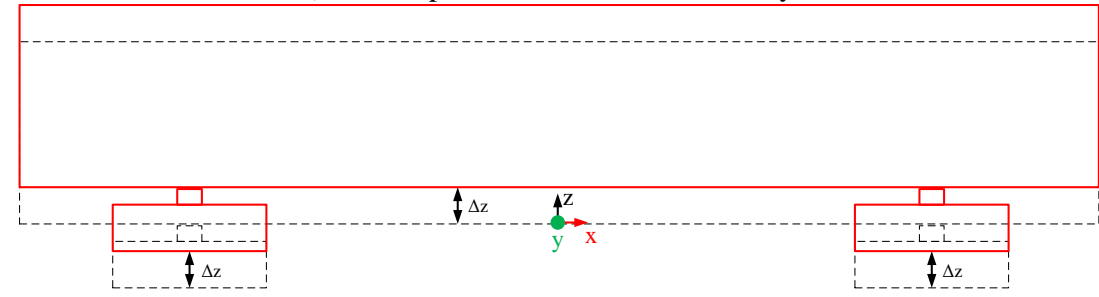

b) Vertical movement of the carbody.

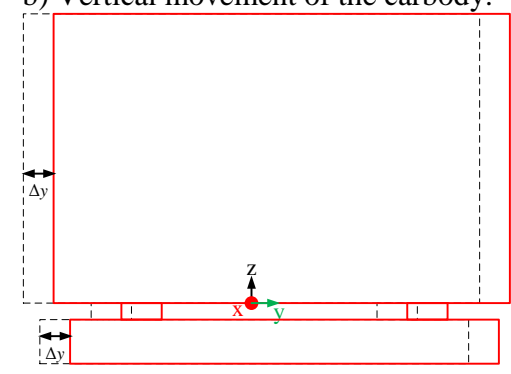

c) Lateral movement of the carbody.

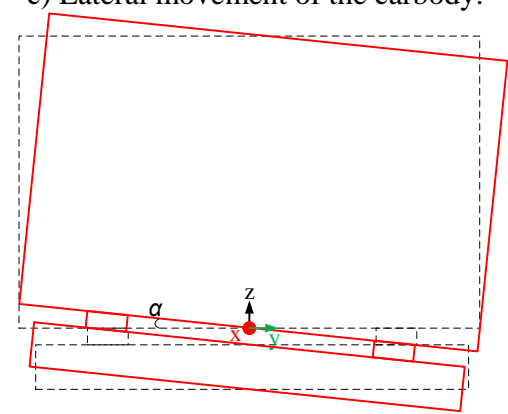

d) Rolling movement of the carbody.

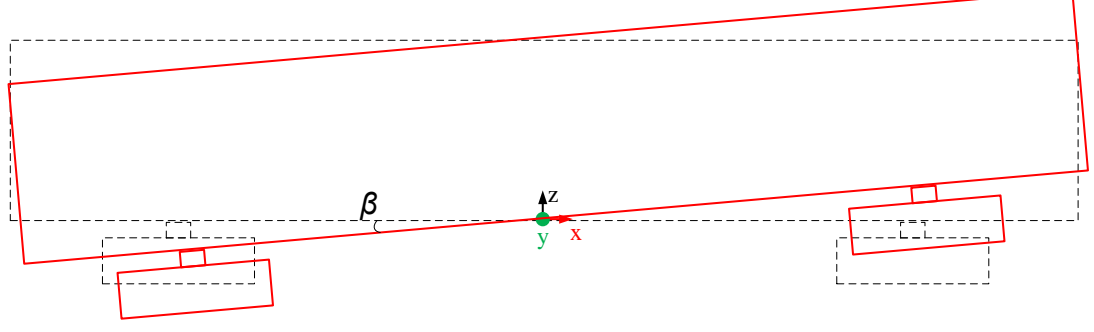

e) Pitching movement of the carbody. 


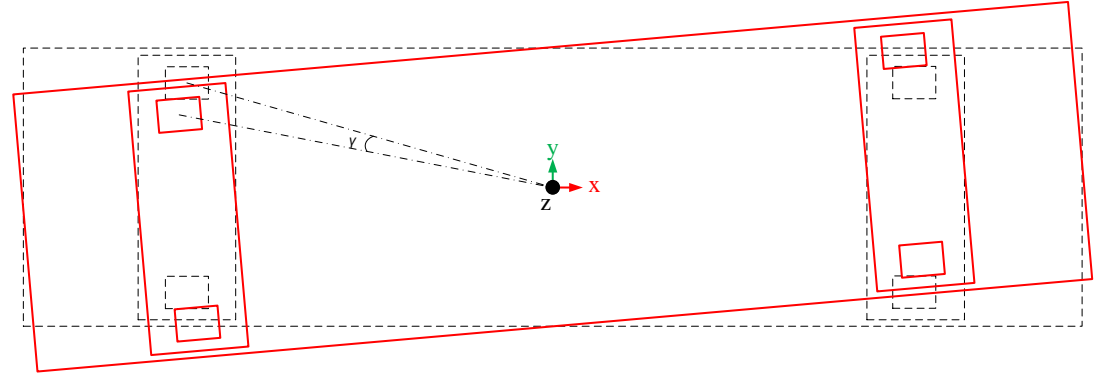

f) Yawing movement of the carbody.

Figure 8 Six typical sports postures

\section{Selection of Modal Test Fixture}

When using the vibration test bench to excite the carbody, it is expected that all the excitation energy of the test bench will be transferred to the carbody [13-14]. If the test bench is rigidly connected with the carbody, the excitation energy of the vibration test bench will be completely transferred to the carbody without being affected by the vibration isolation function of the fixture in the vibration transmission path. However, in the traditional structural free mode test, it is hoped that the stiffness of the boundary support can be small enough, so that the additional influence on the stiffness of the test object is small [15]. In order to discuss the selection method of the fixture when testing the modal parameters of the carbody by using the vibration test bench, the carbody modal test is carried out by using fully rigid and elastic support respectively in the virtual test. Among them, the stiffness of the elastic support refers to the stiffness and damping settings of the secondary air spring of EMU vehicles, and the specific stiffness and damping values of the fixture are shown in the Table 3.

Table 3 Fixture stiffness and damping value.

\begin{tabular}{ccc}
\hline Parameter name & Rigid support & Elastic support \\
\hline Longitudinal stiffness /(N/mm) & $\square$ & 131 \\
Lateral stiffness /(N/ mm) & $\square$ & 131 \\
Vertical stiffness /(N/ mm) & $\square$ & 205 \\
Longitudinal damping (N.s/ mm) & 0 & 6 \\
Lateral damping (N.s/ mm) & 0 & 6 \\
Vertical damping $(\mathrm{N} . \mathrm{s} / \mathrm{mm})$ & 0 & 25 \\
\hline
\end{tabular}

\section{$5 \quad$ Virtual Test Results}

The displacement sweeping frequency excitation is applied in the first six modal frequency ranges of the carbody, and the frequency sweep range is $0 \mathrm{~Hz}-30 \mathrm{~Hz}$, the sweeping frequency step is $0.05 \mathrm{~Hz}$, and each frequency point lasts for 0.5 seconds to obtain the steady state response of the system. Because the movement displacement of the carbody ends is the largest in each movement posture, the acceleration time 
domain signals of the acceleration measuring points located at the carbody ends in the main movement direction are listed, as shown in Figure 9 to Figure 13 respectively.

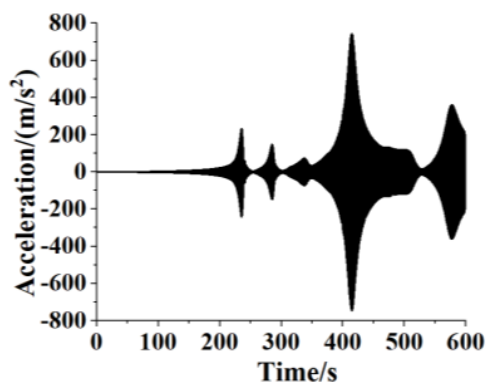

a) Rigid support

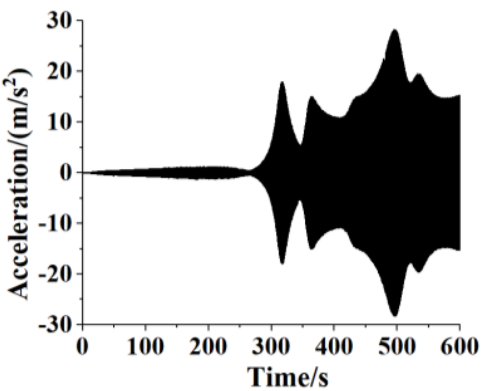

b) Elastic support

Figure 9 Acceleration responses in $z$ direction under carbody vertical movement posture.

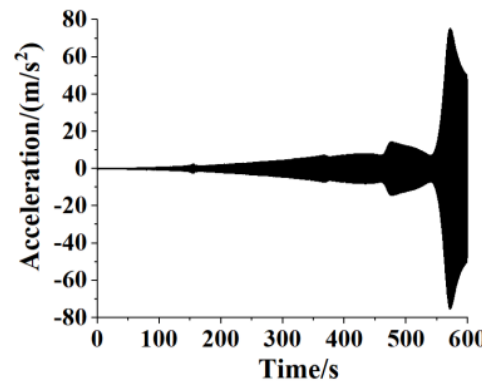

a) Rigid support

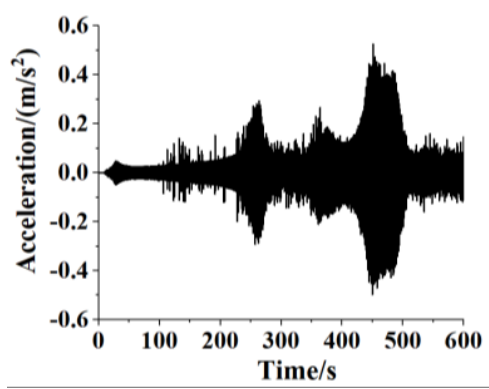

b) Elastic support

Figure 10 Acceleration responses in the y direction under carbody lateral movement posture.

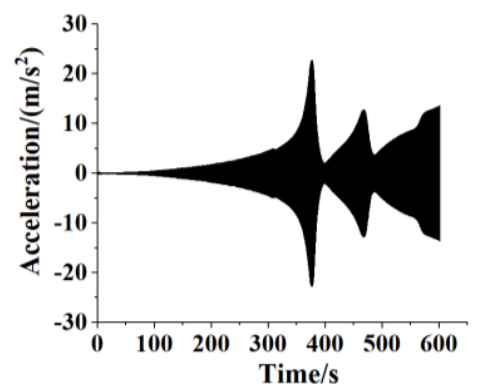

a) Rigid support

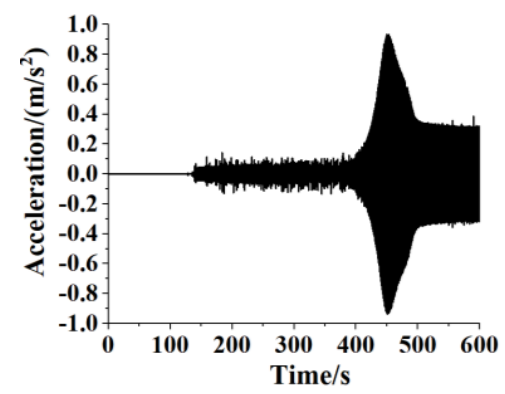

b) Elastic support

Figure 11 Acceleration responses in the y direction under carbody yawing posture.

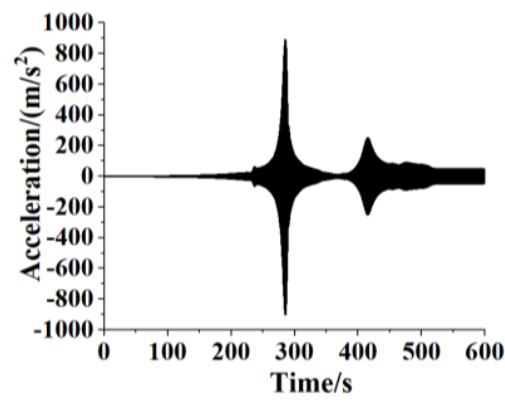

a) Rigid support

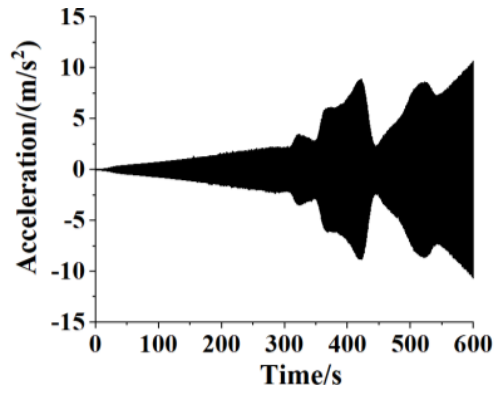

b) Elastic support 
Figure 12 Acceleration responses in the y direction under carbody pitching posture.

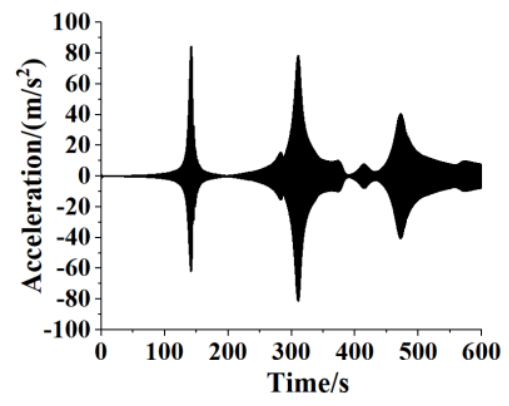

a) Rigid support

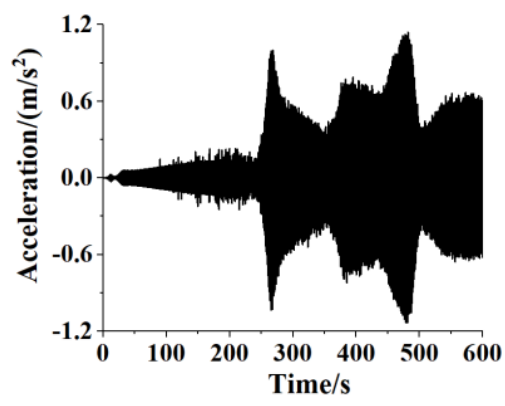

b) Elastic support

Figure 13 Acceleration responses in the $\mathrm{z}$ direction under carbody rolling posture.

Look at Figure a) in Figure 9 to Figure 13. Because of the rigid fixture, all the excitation energy of the test bench is transferred to the carbody. Although the amplitude of the input excitation is small, the acceleration response of the carbody is very large. At the same time, the number of peak values of the time domain signal of carbody acceleration measured by rigid fixture and the occurrence time of each peak value are obviously different from that which was supported by elastic fixture. Looking at Figure b) in Figure 9 to Figure 13, although the elastic fixture is used, the vibration energy of the test bench is attenuated on the path to the carbody, the acceleration response of the carbody after excitation is large enough.

Table 4 shows the identification results of vehicle body modal parameters when rigid fixture is used to support the vehicle body. It can be seen that when the rigid fixture is used to support the carbody to test its modal parameters, the test results are not ideal, because the support stiffness is too large and different from the free boundary of the car body. Through frequency sweep excitation, the first-order breathing mode, the first-order torsional mode and the first-order lateral bending mode in the free mode are not identified, but the vibration modes which do not exist in the free mode appear. At the same time, the error between the identified modal frequency and the theoretical value of the free modal frequency of the carbody is large. The rigid fixture can completely transfer the excitation energy of the vibration bench to the tested structure, however, it can be seen from the acceleration response of the carbody during the sweep excitation in Figure 9 to Figure 13 that a small displacement excitation input will also lead to an excessively high acceleration response of the carbody, which will lead to excessive stress of the carbody and damage to the carbody structure during the test.

Table 5 shows the modal parameters of the carbody to be tested when the carbody is supported by elastic clamps for frequency sweep excitation. It can be seen that different modal shapes of the carbody are identified under different motion postures, and the relative error between the modal frequency of the carbody identified by virtual modal test and the theoretical value is very small. The Figure 14 shows the modal shapes of each order of the carbody identified under the elastic support.

Table 4 Recognition results of modal parameters of carbody under fully rigid support. 


\begin{tabular}{|c|c|c|c|}
\hline $\begin{array}{l}\text { free modal } \\
\text { frequency of } \\
\text { carbody } / \mathrm{Hz}\end{array}$ & carbody & $\begin{array}{l}\text { value of fully rigid } \\
\text { support carbody } / \mathrm{Hz}\end{array}$ & $\begin{array}{l}\text { recognition results of } \\
\text { fully rigid support } \\
\text { carbody }\end{array}$ \\
\hline 13.13 & $\begin{array}{l}\text { The first-order } \\
\text { diamond mode }\end{array}$ & 16.44 & $\begin{array}{l}\text { The first-order } \\
\text { diamond mode }\end{array}$ \\
\hline 15.73 & $\begin{array}{l}\text { The first-order } \\
\text { vertical bending } \\
\text { mode }\end{array}$ & 17.91 & $\begin{array}{l}\text { The first-order } \\
\text { vertical bending } \\
\text { mode }\end{array}$ \\
\hline 17.86 & $\begin{array}{l}\text { The first-order } \\
\text { breathing mode }\end{array}$ & 18.81 & $\begin{array}{l}\text { Torsion in the } \\
\text { middle of the } \\
\text { carbody }\end{array}$ \\
\hline 18.63 & $\begin{array}{l}\text { The first-order } \\
\text { torsion mode }\end{array}$ & 20.65 & $\begin{array}{l}\text { Vertical bending of } \\
\text { the carbody }\end{array}$ \\
\hline 21.26 & $\begin{array}{l}\text { The second-order } \\
\text { breathing mode }\end{array}$ & 22.68 & $\begin{array}{l}\text { The second-order } \\
\text { breathing mode }\end{array}$ \\
\hline 22.34 & $\begin{array}{c}\text { The first-order } \\
\text { transverse bending } \\
\text { mode }\end{array}$ & 23.49 & $\begin{array}{c}\text { Torsion in the end of } \\
\text { the carbody }\end{array}$ \\
\hline
\end{tabular}

Table 5 Recognition results of modal parameters of carbody under elastically support

\begin{tabular}{|c|c|c|c|c|c|c|}
\hline $\begin{array}{l}\text { Sports } \\
\text { posture }\end{array}$ & $\begin{array}{l}\text { The first- } \\
\text { order } \\
\text { diamond } \\
\text { modal } / \mathrm{Hz}\end{array}$ & $\begin{array}{l}\text { The first- } \\
\text { order } \\
\text { vertical } \\
\text { bending } \\
\text { modal } / \mathrm{Hz}\end{array}$ & $\begin{array}{l}\text { The first- } \\
\text { order } \\
\text { breathing } \\
\text { modal } / \mathrm{Hz}\end{array}$ & $\begin{array}{c}\text { The first- } \\
\text { order } \\
\text { torsion } \\
\text { modal } / \mathrm{Hz}\end{array}$ & $\begin{array}{l}\text { The } \\
\text { second- } \\
\text { order } \\
\text { breathing } \\
\text { modal } / \mathrm{Hz}\end{array}$ & $\begin{array}{l}\text { The first- } \\
\text { order } \\
\text { transverse } \\
\text { bending } \\
\text { modal } / \mathrm{Hz}\end{array}$ \\
\hline $\begin{array}{l}\text { Vertical } \\
\text { movement }\end{array}$ & 13.12 & 15.74 & 17.79 & -- & 21.30 & 22.36 \\
\hline $\begin{array}{c}\text { Lateral } \\
\text { movement }\end{array}$ & 13.14 & -- & -- & 18.61 & -- & 22.32 \\
\hline Pitch & -- & 15.74 & -- & 18.67 & 21.29 & 22.36 \\
\hline
\end{tabular}




\begin{tabular}{ccccccc}
\hline Yaw & 13.13 & -- & -- & 18.64 & -- & 22.35 \\
Roll & 13.14 & -- & -- & 18.66 & -- & 22.36 \\
\hline
\end{tabular}

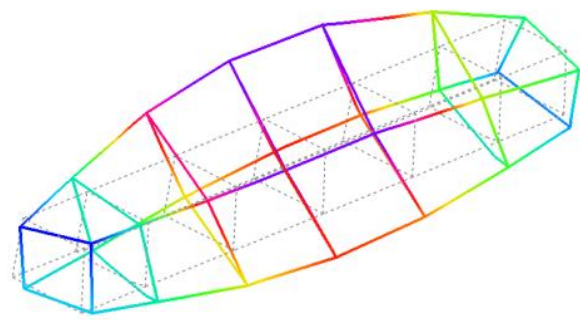

a) The first-order diamond mode

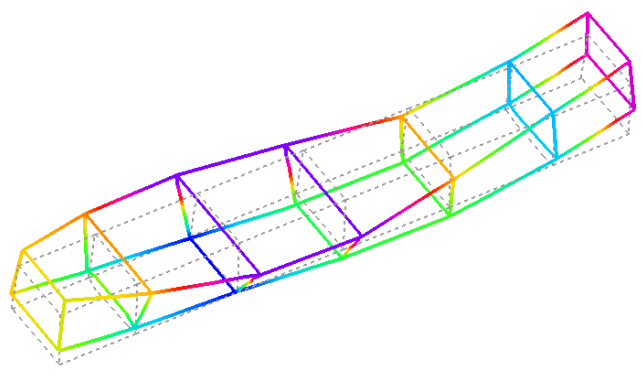

c) The first-order breathing mode

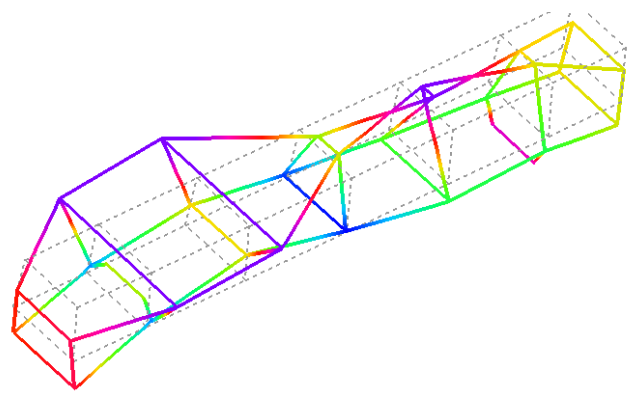

e) The second-order breathing mode

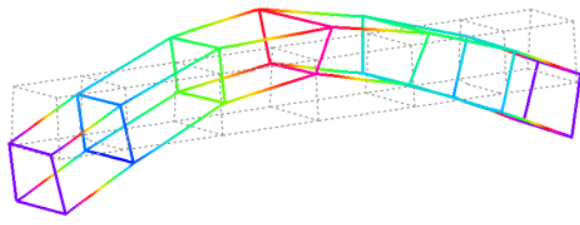

b) The first-order vertical bending mode

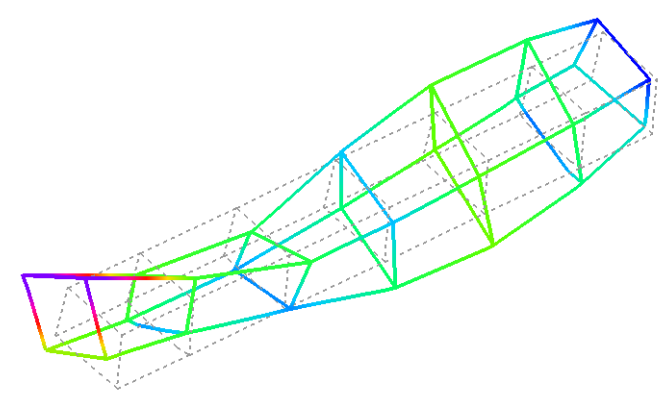

d) The first-order torsion mode

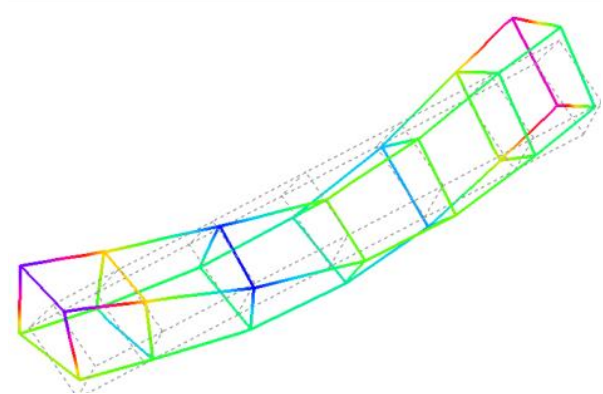

f) The first-order transverse bending mode

Figure 14 Carbody shape.

\section{Conclusions}

Testing the modal parameters of the carbody by using the vibration test bench is quite different from the conventional method by using a hammer or an exciter. The main difference is that the vibration test bench can simulate the actual various motion postures of the carbody, and the carbody to be tested can be loaded with sweep frequency. The support mode and excitation source of the carbody are consistent with the reality, so the test results are true and reliable. When the traditional hammer or exciter is used to test the modal parameters of the carbody, it is necessary to select the support mode and excitation position of the carbody carefully, the boundary conditions of the carbody are different from the reality, which may bring more additional influences. When testing the modal parameters of the carbody by using the vibration test bench, it is also necessary to use the elastic fixture to fix the carbody 
with the test bench. After the excitation energy of the test bench is attenuated by the elastic fixture, it is still enough to excite the various modes of the carbody. Therefore, by simulating the actual running posture of the carbody on the vibration test bench and loading the carbody with frequency sweep, the modal information of the carbody to be tested can be identified more accurately and truly.

\section{References}

1. Ward Helen, Bai Huatong, Guo Jizhong. Theory and experiment of Modal Analysis. M. 2001.

2. Jia Xiaoping, Ma Guangxuan, Liu Dong. Research on the similarities and differences between exciter excitation and hammering excitation in the $M U$ wheelsets modal test. J. Railway Locomotives and EMUs, 2019(2): p. 7-9.

3. Yuan Yuting. Study on the experimental mode of metro vehicle body based on EMD. D. Chengdu: Southwest Jiaotong University, 2018.

4. Peter, Avitabile. Modal Testing: A Practitioner's Guide. M. John Wiley \& Sons Ltd, 2017.

5. Zahid, Fahad. A review of operational modal analysis techniques for inservice modal identification. J. JOURNAL OF THE BRAZILIAN SOCIETY OF MECHANICAL SCIENCES AND ENGINEERING,2020,42(8): p. 1-18.

6. Ma Xingguo, You Xiaomei, Wen Bangchun. Multi-body dynamics simulation for a crankshaft system based on virtual prototype technology. J. Vibration and Shock, 2008(9): p. 155-157+190.

7. Guyan, R. J.. Reduction of stiffness and mass matrices. J. AIAA Journal, 1965, 3(2): p. 380-380.

8. Zheng Ruoyu. Study on lightweight of metro carbody using super element technology. D. Chengdu: Southwest Jiaotong University, 2016.

9. Chen Huaihai, Zhou Chuanrong. Application of modal reduction method in the analysis of vibration characteristics of composite structures. J. Engineering Mechanics, 1997, 14(2): p. 114-120.

10. General Administration of Quality Supervision, Inspection and Quarantine of the People's Republic of China, National Standardization Administration of China. GB/T 32358-2015. Bench test method for rail transit rolling stock. S. Beijing: China Standard Press, 2016.

11. He Li, Zhang Limin. Modal contribution analysis of vehicle's body on static bench test. J. Noise and Vibration Control, 2018, 38(4): p. 96-99.

12. Luo Ren, Shi Huailong. Railway vehicle system dynamics and applications. M. Chengdu: Southwest Jiaotong University Press, 2018.

13. MONCAYO H, MARULANDA. Identification and monitoring of modal parameters in aircraft structures using the natural excitation technique (NExT) combined with the eigensystem realization algorithm (ERA). J. Journal of Aerospace Engineering, 2010, 23(2): p. 99-104.

14. FRANS R. Structural system identification of plane frames based on 
frequency domain decomposition-natural excitation technique. J. Materials Science and Engineering, 2019, 615(1): p. 180-195.

15. Li Jiabao, Xu Cong, Tang Jinsong, et al., Research on modal parameter identification and carbody Supporting stiffness of railway passenger cars. J. Railway Vehicles, 2019, 57(11): p. 1-4. 